\title{
External Assessment of Engineering Programs
}

\author{
K. Ferens \\ Department of Electrical and Computer Engineering, University of Manitoba, Winnipeg, Manitoba, Canada \\ ferens@,ee.umanitoba.ca
}

\begin{abstract}
This paper reports on an Industry Focus Group Forum, which was held 20 October 2011. The purpose of the forum was to obtain local Industry's perception and opinions of the strengths and weaknesses of new engineering graduates from the Department of Electrical and Computer Engineering, University of Manitoba at the time they enter the work force. Key strengths of best-in-class engineering employees were identified, such as attitude, knowledge base, creativity, communication, and initiative. While these were the attributes of best-in-class employees, they represented goals to which new graduates should aspire. The industry members also identified weaknesses of new engineering graduates, such as life-long learning, practical aspects, engineering tools, and communication. The strengths and weaknesses were mapped to Canadian Engineering Accreditation Board attributes for validation. The secondary purpose of the forum was to establish a process by which the Faculty can assess their graduates at the time they enter the workforce. The process involved external opinions of the quality of the Faculty's new graduates.
\end{abstract}

Keywords-Industry focus group forum, assessment, accreditation, CEAB.

\section{Introduction}

An external evaluation should be a mandatory component in any assessment of an engineering program. Most graduates of an engineering program of universities across Canada and abroad proceed to work in industry, and their work in industry becomes the foundation upon which the society grows, culturally, technologically, and economically. Accordingly, to improve the efficiency and competitiveness of industry in a local, national, and global market, the needs of industry, in terms of the attributes of new engineering graduates, must be carefully determined, specified, and met.

The goals of a "research and teaching" institution do not always correlate exactly with the immediate needs of local and national industry. Many professors of "research and teaching" institutions spend much of their time developing research programs to satisfy the research oriented goals of their administration and vision of their university. Consequently, the mindset of a researcher permeates into the teaching of undergraduate students, and the students acquire knowledge, skills, and attitude skewed towards research, rather than what industry requires. Developing products does not require focused skills in doing academic research. While research has a part in the R\&D process of industry, the research part is typically a much smaller role in product development.

Therefore, an external assessment of an engineering program is important to establish the needs of industry and to (re)focus curricula.

This paper reports on an Industry Focus Group (IFG) forum, which took place on 20 October 2011. The objective of the forum was to obtain Industry's perception of both the strengths and weaknesses of new engineering graduates at the time they enter the work force. The participants of the IFG forum identified missing knowledge, skills, and attitudes in new graduates. In addition, they identified key attributes which make engineering employees best-in-class in their field; these key attributes were intended to be targets to which new engineering graduates can aspire.

The IFG was comprised of industry members from several disciplines, including Bio-systems Engineering, Civil Engineering, Electrical and Computer Engineering, and Mechanical and Manufacturing Engineering. The forum focused on a cross-section of different engineering functional areas including requirements, architecture, modeling, design, quality assurance, development, technology transfer, manufacturing, supply chain, regulatory compliance, profession, ethics, impact on society, and supervisory management. The IFG was comprised of 25 industry members from the disciplines of Bio-systems Engineering, Civil Engineering, Electrical and Computer Engineering, and Mechanical and Manufacturing Engineering. There were 7 directors, 9 managers, three department heads, one team leader, and 6 R\&D engineers. There was a broad range of industry sectors represented: hydro, structural, hospital, telecommunications, information security, aerospace agriculture, mechanical, pharmaceuticals, and bio-systems.

The IFG forum was also attended by a contingent of 10 faculty members, including one associate dean, 6 department heads and associate heads, and two professors. The results of the forum - the identified strengths and weaknesses of new graduates - will be made available to faculty members, with the intension that they be used as input to help reinforce, modify, shape, and restructure programs at the Faculty of 
Engineering, University of Manitoba.

\section{Related Work}

The study conducted by [1] allowed new graduates to give their own opinions on how well they were prepared for work in industry. New chemical engineering graduates were interviewed after having left the educational institution and had begun working in industry. Rather than sending out surveys, this work interviewed the new graduates, which allowed in-depth exploration of the topics addressed. The new graduates found that their technical background, problem solving skills, formal communication skills and lifelong learning abilities were identified as strengths, but working in multi-disciplinary teams, leadership, practical preparation and management skills were identified as weaknesses. While this study can be interpreted as an external assessment of new graduates, a possible problem with this approach is that the perceptions the new graduates have of their own abilities may not necessarily agree with the perceptions of their employers.

The work done by [2] aimed to identify the most important attributes a new engineering graduate should have to be successful in engineering practice. Their approach was to identify the top performers of new graduates in industry and interview them and their employers. The study found that success in industry requires a combination of technical expertise and non-technical attributes, such as communication, interpersonal skills, and emotional intelligence.

An industry focus group forum has number advantages over other assessment methods. Because a forum is a group interaction, topics may be discussed by the group. Such discussion will bring out the common concerns and identify the outliers. Surveys and questionnaires are more difficult to implement because they require planning and a great deal of thought placed into the questions asked.

This work is a continuation of past forums [3].

\section{Main Results of the Forum}

\subsection{Part 1: Strengths of New Engineering Graduates}

The first part of the forum asked the industry representatives to give their perception of the prioritized strengths of new engineering graduates (Fig. 1). The entire group took part in this session. The group was asked to think about one or more employees who represent the best-in-class engineer. What kind of traits separate or distinguish these employees from the rest? While this question did not explicitly limit the candidates to new graduates, these key attributes were intended to be targets to which new engineering graduates can aspire.

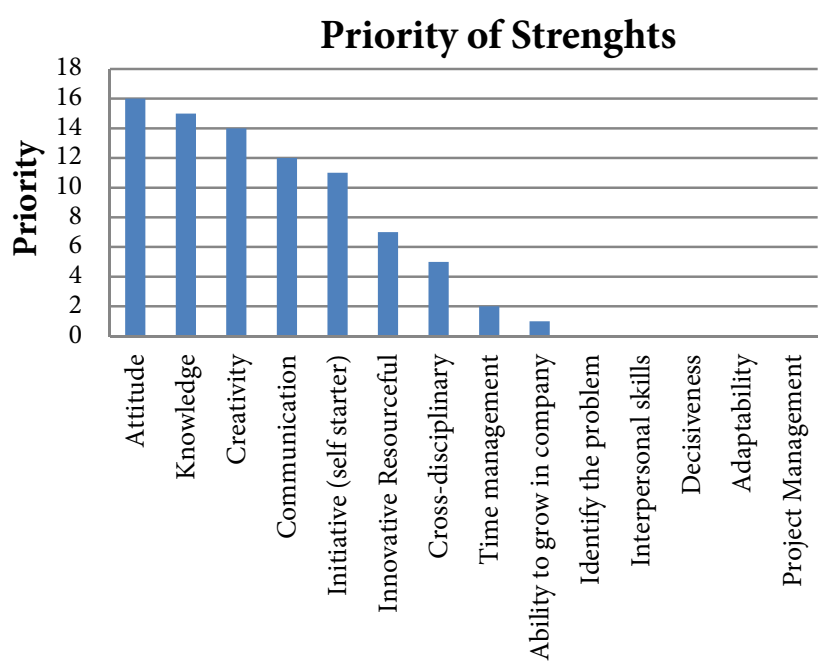

Fig. 1 Perceived strengths of new engineering graduates.

\section{1) Attitude}

Most industry representatives voted that attitude was the most important trait of a successful engineer, but there were few comments to support that affirmation. Many representatives knew that attitude was the most important attribute, but they could not identify exactly what makes a good attitude. The few comments made were Graduates join company with enthusiasm and a positive attitude; understands work ethics; professional point of view; considers employment as not just a job, but a lifelong career; has definite professional attitude; reliable; shows initiative; and pursues new skills The inability to uniquely identify attributes of attitude is expected, since attitude is a combination of several attributes. Indeed, some of the comments involved other related attributes, such as professionalism, ethics and life-long learning.

\section{2) Knowldege}

Many industry representatives felt that every engineer requires a solid knowledge base. Moreover, the knowledge base should be broad in range. For example, the Bio-systems discipline requires knowledge to be multidisciplinary. Other discipliners agreed that the knowledge base should be applied and basic science/knowledge skills (implications felt over time) and a business knowledge/impact (understanding between profit and revenue). The electrical discipline stated that it is critical that engineers understand the fundamentals, and have the ability to apply the best solution and best practices to a given problem. The mechanical discipline agreed that the technical skills are generally there and students from University of Manitoba are getting training on a wide variety of topics; so, knowledge range is broad so most students will at least be able to find out where they need to go to get answers for certain topics. 


\section{3) Creativity}

Many comments were given in regards to the creativity requirement for engineers. Good engineers do not just give the answer they've seen before, but they approach the problem in different ways. A good engineer needs to be innovative and resourceful to produce positive change, and the creativity leads to forward-looking results. However, a good engineer knows that at times creativity can hinder progress; a good engineer knows how to prioritize and understands when to be creative to ensure project completion. A good engineer needs to understand the broad implications of decisions to the good of the company, and needs to see the big picture. Above all, knowledge is critical to be creative.

\section{4) Communication}

The best-in-class engineer excels at communication. Many representatives commented on the ability of a best-inclass engineer to transfer their ideas, technology, and knowledge to others. The ability to effectively communicate is not only important for the individual, but is critical for the company. For example, many designs must be passed along several ancestral branches of the product lifetime. The original designer may not be available for inquiry; so, effective documentation is critically important.

\section{5) Initiative (Self Starter)}

The best-in-class engineer has the ability to work independently. A supervisor of a best-in-class engineer does not need to provide constant step-by-step guidance about assigned tasks, designs, and product development process. A best in class engineer takes a problem statement, and then proceeds to develop a solution independently. If question arise during the process, those questions would be accompanied with potential and alternative solutions, rather than empty questions looking for direction.

\section{6) Innovative Resourceful}

The computer discipline commented that a good engineer has the ability to apply new or a previously existing body of knowledge, in a resourceful or creative manner, to create something new or of value (i.e., article, system, process, method). Other comments were that the best-in-class engineer shows an ability to cope with difficult problems and situations; keeps the common goal in focus at all times; and a shows an ability to approach new problems with a logical and engineering methodology.

\section{7) Life-long Learning}

The electrical discipline commented that a best-in-class engineer has a definite ability and willingness to learn new ways to solve problems; has the attitude and understanding that learning is life-long; has the realization and knowledge of what else is out there; has broad network of contacts and experts; and knows where to get the expertise on demand. New grads begin their careers realizing there is much more to learn.

\section{8) Teamwork and Leadership}

A best-in-class engineer works well with others to accomplish a common goal; can lead a team of technical and non-technical members; is a team player; understands concepts from broad areas; and can lead multidisciplinary groups.

\section{9) Interpersonal Skills}

A best-in-class engineer has the ability to get a room of people to buy into an idea; has excellent customer relations; while one may be very knowledgeable, he/she may not be able to "sell" their ideas to others; engage with others; aspire to be like others in team; and shows distinct ability to operate within business organizations through social communication and interactions.

\section{0) Project Management}

Although project management was not commented on by all disciplines, it was somewhat important: a best-in-class engineer is able to manage time effectively; able to effectively prioritize workload; very productive, on time, and on budget; able to multi-task effectively; understand product lifecycle and the business impact; getting the job done, on time, within budget - according to specifications. (Constraints: schedule, requirements/specifications, cost); and shows considerable planning and exercising control over the amount of time spent on job related activities to increase efficiency or productivity in the company.

\subsection{Part 2: Weaknesses of New Graduates}

The second part of the meeting asked the IFG members to break out into their disciplines and discuss the discipline specific weaknesses of new engineering graduates.

\section{1) Life-long Learning}

The Bio-systems and Electrical disciplines stated either that new graduates don't understand the concept of the lifelong learning attribute, or don't care enough to pursue it. Life-long learning is becoming more relevant because of the incredibly increasing rate of technological change, especially since Bio-systems engineering is a multi-disciplinary field. New graduates are unsure of their responsibility to go out and collect facts within the organization and also from outside sources. New grads need to know how to search for information needed to solve a new problem. When encountered with a new problem, they behave like "deer confused by headlights". New grads are unsure of career 
path, and they don't know what career path lies ahead.

\section{2) Knowledge Base}

The Computer, Electrical, and Mechanical Engineering disciplines identified several areas in knowledge base, which were lacking in new graduates. The Computer Engineering discipline mentioned areas of release/code management (version control); software development life-cycle management; analysis and testing (importance and implications thereof). New graduates need to know more about standards and regulations (pertaining to software), and about formal methods of design, risk assessment, validation, software version control. Design projects in many industries involve incorporating several different requirements into product development - e.g., regulatory requirements, requirements of standards, and requirements of design specifications - which apply to all aspects of the design life cycle, from initial feasibility studies, to defining design requirements and specifications, to verification and validation, to production. This design process is important for a new graduate to be aware of when entering the workforce.

The Electrical Engineering discipline stated that new grads lacked knowledge in power flow and power system protection, system design and operation, and fundamental electromagnetic concepts. Most new grads showed unsafe practice in high voltage environment.

The Mechanical Engineering discipline states that new grads lacked fundamental knowledge with specific application to local industry, e.g. turbomachinary, HVAC, vibration, compressible flow. HVAC is typically missing. The Department spends far too much time even in later years on math.

\section{3) Engineering Tools}

The Computer and Mechanical Engineering disciplines identified several areas in which new graduates were lacking in knowledge and experience using engineering tools. The Mechanical Engineering discipline states that new graduates need exposure and use of: CAD, drafting, 3D solid-works, and revit (industry standard software). New graduates need a wider range and exposure to $3 \mathrm{D}$ modeling (why become experts at only Solid Works or Pro-E)? Hands on skills are generally lacking. Basic skills with tools, machinery, plumbing and electrical components are lacking. We spend several weeks of training to get new graduates up to speed in design work using CAD software.

The Computer Engineering discipline stated that new graduates lack knowledge in using software forums/ or communities (available resources/sources of information) for direction/guidance/sharing of knowledge (e.g., "StashDot.org", "Stack-overflow", etc.). They need to know how to use more software accessories, such as JCL and Make-file). They need more familiarization with FPGAs and $\mathrm{C}$ programming mode in Python environment.
The Electrical discipline mentioned that new graduates need to know licensing implications (knowledge of use); more exposure to new operating systems; and adding value to off-the-shelf hardware.

\section{4) Practical Aspects}

All disciplines commented on the lack practical experience in new graduates. In the mechanical area, new graduates lack experience in industrial relevant problems, practical hands-on experience (shop, wiring etc), and equipment sizing and selection (pumps, etc). In the biosystems area, new graduates seem like they have never been to a job site before; they lack of confidence; they present themselves as Jack of all trades, but really they're master of none. We need to hold hands of new graduates.

\section{5) Communication}

The Mechanical and Electrical disciplines commented that new graduates need to improve on their communication ability. The Mechanical discipline identified that general soft-skills are lacking, such as writing of technical reports, installation manuals, and report summaries. The Electrical discipline stated that new grads don't know what an acceptable report is; reports too long. They do not identify needs of the audience, and they give cryptic email messages.

\section{Conclusions}

This paper reports on an Industry Focus Group Forum, which was held 20 October 2011. The purpose of the forum was to obtain local Industry's perception and opinions of the strengths and weaknesses of new engineering graduates from the Department of Electrical and Computer Engineering, University of Manitoba. The IFG Forum is intended to be a continuous, bi-annual, and iterative process, which gathers opinions from local industry and uses those opinions to improve the educational institution.

\section{References}

[1] R. Martin, B. Maytham, J. Case and D. Fraser, "Engineering graduates' perceptions of how well they were prepared for work in industry," European Journal of Engineering Education, vol. 30, no. 2, pp. 167-180, 2005.

[2] G. Scott and W. K. Yates, "Using successful graduates to improve the quality of undergraduate engineering programmes," Eur. J. Eng. Educ., vol. 27, no. 4, pp. 363378, 2002.

[3] K. Ferens and M. Friesen, "Industry Focus Group Forum for Engineering Program Assessment," in International Conference on Frontiers in Education: Computer Science and Computer Engineering, Las Vegas, 2011. 